\title{
Expeditionary Learning: A Low-Risk, Low-Cost, High-Impact Professional Development Model
}

Chris Carlson-Dakes, Alice Pawley

University of Wisconsin-Madison

We describe a low-risk, low-cost, high-impact professional development program to help faculty, instructional staff, postdoctoral fellows, and graduate students create space in their lives to explore the diversity of their campus community and reflect on beliefs about teaching and learning in higher education. Along with small group discussions, participants have "expeditions" onto campus to explore learning situations and academic life in ways that they have never before experienced. We describe our theoretical model, programmatic and evaluation structure, and some participants' insights into why they participated and what they learned from our first implementation.

\section{Introduction}

"This program has helped me realize that learning encompasses the mind, body, and the soul. We do a great job of nurturing and developing our students' minds, but how do we nurture their body and soul?" This question was posed by "Greg" after he participated in a semester of expeditionary learning. Expeditionary learning is a small group-based professional development program designed to expose participants to diverse campus resources and approaches to teaching and learning, housed in the University of Wisconsin-Madison's Delta Program for Research, Teaching, and Learning. Greg attributes his insights into this question to his participation in expeditionary learning because, despite his incredibly busy and regimented schedule, this was an opportunity to "treat himself" and permit himself time to open up to 
new ways of thinking about his teaching and undergraduate learning. Based on his experiences in the program, he proposed to his department's undergraduate curriculum committee including at least a one-credit requirement for undergraduate students to take a course outside the engineering curriculum to nurture more than their "engineering mind," by considering students as whole beings, incorporating care for their intellectual, physical, and emotional growth.

This chapter presents a low-risk, low-cost, high-impact professional development program designed to create opportunities for people like Greg to feel inspired and energized and to bring to life their new insights. The program helps people create a space to reflect on their personal choices of how to balance institutional pressures with a personal need to feel energized about their work. We have been intentional in our efforts to develop a program that requires minimal staff preparation and resources to provide low-risk opportunities to embrace the existing diverse community in a way that has potential for significant impact on individuals and institutions. Small group (seven to nine people) meetings are held once every two weeks for one and one-half hours and require only one facilitator and little preparation. During the off weeks between group meetings, participants venture out on "expeditions" onto our campus to explore learning situations and academic life in ways they have never before experienced.

This chapter describes our underlying model of professional development and details how we have brought it to life through the expeditionary learning program. Accompanying our programmatic structure and experiences as facilitators, we share participants' insights into why they participated, what they learned from the experience, and the impact the experience had on them.

\section{A Model for Professional Development}

The expeditionary learning (EL) program can exist as a stand-alone program or as part of a suite of program offerings. Compared to other models of professional development programs that require large start-up efforts or existing infrastructure, EL is relatively easy to adapt and implement on its own. It can also be easily adjusted to fit within many existing and diverse programmatic structures currently in place on different campuses.

We are fortunate to have it as one part of the core of a group of professional development programs, courses, internships, and other activities known as The Delta Program for Research, Teaching, and Learning (see 
http://www.delta.wisc.edu), itself part of the National Science Foundationfunded Center for the Integration of Research, Teaching, and Learning. The full spectrum of Delta offerings is designed to provide access to professional development for the widely diverse needs, interests, and levels of commitment for all interested in advancing the teaching and learning culture of science, technology, engineering, and mathematics (STEM) fields. We approach this broad mission by advocating the integration of three key concepts: teaching-as-research, learning community, and diversity.

Our focus on all STEM disciplines is central to our mission, but the EL program can easily be adjusted for a single department or expanded beyond the boundaries of STEM. Similarly, the three concepts of teaching-asresearch, learning community, and diversity that form the foundation for our program can be adapted to the cultural and institutional priorities of other institutions. To give context to how we have fit within our cultural and institutional priorities, and to help explain how we have integrated the three concepts into our implementation of the program, each concept is described below. They are presented as independent theoretical concepts, but in practice they are very connected.

\section{: Teaching-as-Research}

Teaching-as-research is based heavily in our university culture of research and directly stems from the growing professional development emphasis on the scholarship of teaching (Boyer, 1990). One of our main purposes in Delta is to encourage current and future teachers, consisting of faculty, instructional staff, postdoctoral fellows, and graduate students, to consider teaching as a process of inquiry. This follows a model that builds on their strengths as researchers in the context of teaching and emphasizes the need for teachers to follow four primary steps (see Figure 18.1):

1) Develop and clearly articulate the goals for student learning

2) Plan and implement teaching strategies that help their students meet these goals

3) Design evaluative materials to assess whether students have met these goals

4) Close the loop by revising their teaching based on the information gathered in these evaluations 
FIGURE 18.1

Teaching-as-Research Model

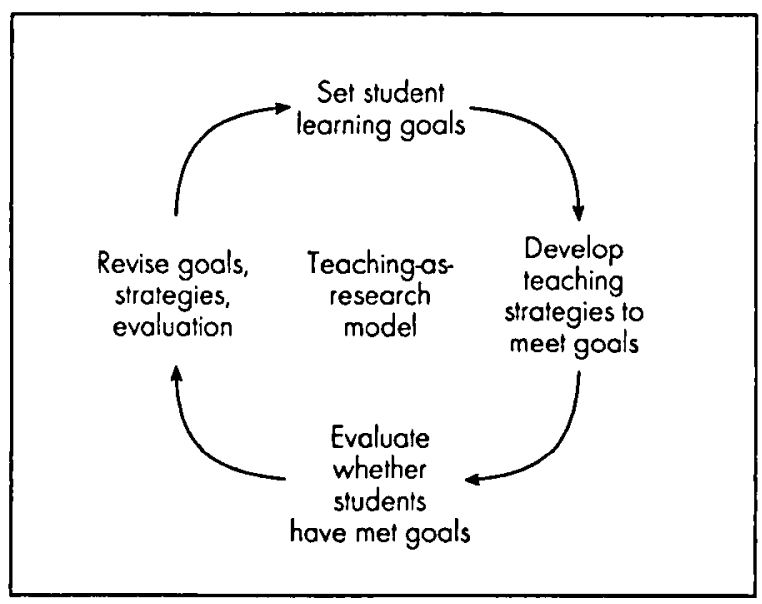

Integrating the teaching-as-research process into the expeditionary learning program builds on the strengths of scientists and engineers as researchers and inquisitive problem solvers, and provides them with a structure and supportive environment to engage these familiar research-based processes in a new environment-that of their teaching.

\section{Learning Community}

Expeditionary learning also incorporates principles of learning community development throughout its design. Our campus has a strong history of undergraduate residential learning communities (e.g., Allen, 1999; Altschuler \& Kramnick, 1999; Brower \& Laines, 1997; Mattmiller, 1996; Meikeljohn, 1928) that we have built upon through the Delta Program. In particular, we focus on principles of encouraging shared discovery and learning and developing meaningful connections between all participants (graduate students through faculty). Building on these principles as fundamental to the process of learning community development, three structural elements are also critical-the academic, social, and physical space (Brower \& Dettinger, 1998). For the expeditionary learning groups, teaching-as-research serves as the academic "content" element, with frequent small group social interactions within a physical setting of the common areas of the Science House, our physical home on campus. 


\section{Diversity}

Representatives from higher education and industry have strongly emphasized the importance of skills related to working in complex and diverse settings (see Durand, 2004; Koehler \& Miranda, 2004). Faculty and staff play a vital role in preparing students for work and as a safety net for mentoring during a critical time in students' lives. As such, we must be able to teach and model the skills we hope to embody in our students. An often-debated issue in higher education is the question of how to facilitate the development of respect for diverse communities so that we can connect across differences, not be divided by them. We believe one way is to have faculty and staff who are confident in their ability to respond to diverse needs and who model respect, tolerance, equity, and inclusiveness in teaching.

As a large Research-1 university, our campus environment is filled with possibilities for exploring diversity-multiple ways of teaching and learning as well as diverse teachers and learners. But for a variety of reasons, despite the abundance of opportunities, many people working within the university community rarely take advantage of these opportunities. Expeditionary learning is specifically designed to encourage more people to experience and participate in the multiplicity of discussions and learning activities already happening on our campus in order to broaden our collective understandings about each other as colleagues and as people.

Furthermore, our campus community consists of people in multiple roles and career stages. To create inclusive and broad learning experiences, expeditionary learning intentionally brings together graduate students, postdoctoral fellows, instructional staff, and faculty to form program groups, providing everyone with the opportunity to learn from and with each other. The cross-generational nature of this program is just one dimension of diversity that has been structurally integrated into participants' experience.

As part of the larger Delta Program, we explicitly connect expeditionary learning with other related programs, courses, and activities and ensure that participants from diverse backgrounds and experiences feel included. Through our emphasis on learning community principles, we hope that participants will be inspired to change the isolating and product-oriented character of higher education often found in science and engineering classrooms, particularly at research institutions. We use teaching-as-research, learning community, and diversity together to form the backbone for organizing educational reform in STEM fields. The expeditionary learning program is just one example of how people can creatively build on existing resources to provide a relatively low-cost way to have a significant impact on the teaching and 
learning culture. We hope that this proves useful for aiding other innovations on other campuses.

\section{Organization of Expeditionary Learning}

The expeditionary learning program stems from the Expeditionary Learning Outward Bound program for K-12 education (Cousins, 1998, 2000) and was modified to be applicable in a higher education setting. We have additionally grounded our program in experiential adult learning theory by emphasizing critical reflection throughout the experience (Apple, 1996; Cunningham, 2000; Henry, 1989; Kolb, 1984; Wilson \& Hayes, 2000). The programmatic structure encourages participants to develop new questions about teaching and learning, create methods to explore them, and feel supported by their group in their journey to discover new answers.

\section{Program Logistics and Structure}

Our experience with this and other similar programs shows that community is fostered by forming groups of seven to nine people (including graduate students, postdoctoral fellows, instructional staff, and faculty) that meet semimonthly for one and one-half hour discussions for an academic semester (see Appendix 18.1 for semester schedule). Once every two weeks, individuals, pairs, or groups of participants take a campus expedition to experience a learning activity or environment that would help to stretch their understanding of diverse approaches to learning and teaching. These experiences help participants raise new questions for themselves to discuss with the group the following week. In the weeks between the expeditions, the groups meet to engage in a facilitated discussion of what they experienced the previous week, what they learned, what new questions emerged, and the implications those questions may have on their teaching. Following a talking circle model for group discussion (e.g., Running Wolf \& Rickard, 2003), individuals are given an opportunity to share the stories of their expedition before the group engages in open discussion of the expeditions. Occasionally, the discussions are supplemented by a short reading.

During the meetings, participants developed and refined ideas for future expeditions based on new insights, questions, and issues that were raised. The influence of the learning community principles of shared discovery and meaningful connections on the experience of participants was evident to us as they discussed their future plans in a public forum with the group. The act of describing their plans in public strengthened participants' commitment to 
actually do their expedition because members in the group now counted on the others to report back on their experiences and formed their own plans around those of others.

\section{Recruitment, Participation, and Level of Involvement}

Participation is voluntary with no extrinsic rewards. The minimum expectations for participation are to attend and actively participate in all seven group meetings and go on all four expeditions (average of approximately one and one-half hours per week for the entire semester). Recruitment took place through mass emails, personal invitations from the facilitators to those who had expressed past interest, and recommendations from other Delta staff and participants. For the fall 2003 semester, we had two teams of eight participants each (eight graduate students, three postdoctoral fellows, and five faculty). One team had a single facilitator; the other had two co-facilitators.

Based on external circumstances and individual levels of commitment, people took on their own level of engagement with the program. Many attended most meetings; a few missed an expedition. Some representative expeditions from fall 2003 include:

- Visiting a library or campus museum participants had never visited to observe the physical surroundings, glance through research journals from a different discipline, and experience a different environment for learning

- Visiting a resource center for helping students of different abilities

- Interviewing someone in a different professional role about his or her job and position in the university

- Attending a seminar on an unfamiliar topic or from another department

- Visiting and observing the dynamics in a building that houses disciplines different from the participants' own

- Visiting and observing undergraduate hangouts on campus, such as downtown bars or the student union

\section{Framing Questions to Close the Loop}

We modeled the teaching-as-research process for the program the way we hope participants will do for their courses. This process served as the basis of research for this chapter and centered on the following research questions: 
- Do participants leave the program "changed" in some lasting way? If so, in what way? If not, why not?

- What aspects of the program were most important to participants' personal experiences?

- In what ways can we improve the program implementation for the next iteration? (For this, we need to know why individuals initially decided to participate, and why they continued their participation throughout the semester.)

\section{Data Collection}

The data collection was largely formative, qualitative, and ongoing (to promote continuous improvement in the program). In addition to weekly facilitation and meeting notes, we conducted formal mid-semester, open-ended written evaluations and end-of-program surveys. The semester following the program completion, we invited all participants to be interviewed to delve deeper into the core issues that emerged from the written evaluations. Eight of 16 participants agreed to 30-minute tape-recorded interviews. We found that these interviews provided the richest, most in-depth data about participants' experiences and changes and serve as the core of the data analysis that follows.

\section{Data Analysis}

We used thematic analysis and pattern formation to analyze the data (Barley, 1990; Glesne \& Peshkin, 1992; Robson, 2002). The participants' written feedback, our interview field notes, and weekly facilitator meeting notes led us to the broad categorical themes of:

- Programmatic elements that attracted people to participate

- Reasons people continued their participation

- What participants gained from their experience

Within these three themes that served as a categorical framework, we placed specific comments and observations identifying a subset of common response themes. As with any qualitative study, unexpected themes emerged (e.g., disadvantages of participation and a desire to participate in the program again). The unexpected themes along with the thematic clusters that 
formed around the central questions were used to construct an outline for the ideas and responses reported next.

\section{Results}

Presented here are the lessons learned about the main themes: programmatic elements that attracted people to participate, reasons people continued their participation, and what they gained from their experience. The first two themes are closely linked and are reported together.

\section{: Programmatic Elements That Attracted People to Participate and Reasons People Continued Their Participation}

We expected that people would want to participate in EL because the core purpose of the program was to help people feel connected with others interested in teaching and learning, and they wanted to learn about diverse teaching and learning resources and approaches already available on our campus. These reasons did come up frequently in participants' responses, but we did not expect participants to highlight the faculty connection as strongly as they did. Faculty participants indicated their desire to meet other faculty interested in teaching and learning, and several graduate students and postdoctoral fellows said they wanted to hear about the career experiences of the faculty members in their groups.

A common reason identified by participants for initial interest was that the time commitment was not excessive. It is our experience with programs that require similar time commitment that $25 \%-30 \%$ of the people who initially sign up eventually drop out because of schedule conflicts and other priorities. We hypothesized that participants would continue to attend EL meetings if they found the content of the discussions interesting and the expeditions as worthy of their time as other priorities. The importance of the ease and impact of the first expedition was evident as it helped to build commitment to continue with the program. A common reason for continuation was that it was easy to participate, with minimal time commitment and effort for the amount they gained. The semimonthly meetings were frequent enough to develop some group cohesion but not so frequent that attending was a burden. The two weeks between meetings gave participants flexibility to choose an expedition and carry it out within their own schedule constraints.

Several participants said that once they had initially committed to attending EL sessions, the program's structure helped them make time to 
think about their teaching practices. This activity was something they obviously valued, but without the commitment to the program, even before they knew much about it, they would not have allowed themselves the luxury of this reflection. One senior faculty member noted,

- "I had this assignment, and I had this structure, and I went out and did [the expedition]. And I had to make time to do this. If I wouldn't have had the structure of this program, I wouldn't have made the time. I would have been totally busy with other things and wouldn't have thought to do this. But, given that this is a structure, and it was like treating myself to get out and play with this, that was an enjoyable thing to experiment with."

We were surprised to note that among the personal reasons people gave for continuing, a strong theme of commitment to the group, and a feeling of obligation and accountability to the other participants emerged as the primary reasons for following through with their plans and coming prepared each week. Although it is entirely feasible for individuals to take the initiative to spontaneously pop into libraries they have never visited, attend a seminar from another discipline, or to read articles on teaching and learning, participants said that doing this would have been very uncharacteristic if left to themselves to do it. It was the group setting and sense of accountability they had for the group that propelled them to act in this otherwise unnatural way. Some said it was the sense that they would be letting the group down if they failed to go on their chosen expedition. In reference to the strength of the community, one graduate student participant said that once the program was over, she didn't feel like doing her own expeditions because there was "no one to share it with."

An additional reason people participated was because of reputation and previous positive experiences in other teaching and learning programs led by the facilitators. They noted that the formality of a program run by people whose job it is to structure these sorts of activities gave it credibility and that knowledgeable facilitators opened doors and access to resources the participants didn't even know existed. The presence of knowledgeable facilitators was another reason to continue: they felt as if they could not have made the initial discovery of campus resources on their own, or if they could, they were not able or not qualified to find "good" resources. There was also a feeling that the formally structured program gave participants "programmatic permission" to do things they otherwise would not do. One participant spoke about her reliance on the facilitators and the structure of the program to filter resources to explore: 
- "[The expeditions are things] people could do, but they most certainly wouldn't do it ... they wouldn't be aware of it. You guys go out there and you... steer people toward it. [You] have the discussion afterward where people come back and they can say what they thought was really interesting and how they're going to relate it to their own thing. I think that's the extra you get from having a program [to structure these activities]."

Expeditionary learning was also seen as a "fun break" in a relaxed atmosphere different from the working environment of the participants' offices, departments, or labs. Participants talked about finding a sense of adventure and of doing something new: "I'm always looking for something new," "I get to go on expeditions," and "It's an opportunity to treat myself." Again, these opportunities could have been self-generated, but participants pointed to the value of having a group who is counting on them to show up. This constructive peer pressure prompted people to actually take these much-needed breaks that occupational stress research shows are necessary for sustained and more productive work (Salvendy, 1997).

\section{What They Gained From Their Experience}

We expected participants to gain information about the existence of various diverse campus resources, as well as feel as if they were part of a community of people who cared about teaching and learning. Our participants reported that they did personally gain in these two areas, but they were just two among many additional gains. They also pointed to the connections they made with faculty, and others found inspiration to apply to their classrooms the things they had learned from their expeditions and group discussions. Still others shared that they felt they had grown in self-awareness regarding their interest in teaching. One participant wrote in her end-of-semester evaluation,

- "This group has made me seriously reevaluate my job prospects and now teaching is very high on the list whereas before $I$ merely saw it as a backup when other possibilities were exhausted."

Most participants said they had gained an increased awareness and interest in teaching and in different possibilities for reconceptualizing their approaches. Their experiences helped them think about their practice in new and different ways. For example, from something as simple as visiting a library on campus they had never visited before or exploring an unfamiliar part of campus, participants generated many new questions for themselves and their colleagues during group discussions. Some of these included: 
- How can I bring art and creativity back into engineering design? (from visiting the art museum)

- What are students' thoughts and feelings of their ethical and social responsibility in education once they leave college? (from walking through the law building)

- The way I've conceptualized education is in conflict with how education works. How can I bridge the gap of this paradox? (from seeing similar challenges in other disciplines)

- What is the environmental impact of the science we do? (from looking differently at the physical environment of the campus)

- What are humanities and social science student perceptions of the sciences in their lives? (from visiting the humanities building)

- How can we nurture the body and spirit as well as we nurture the mind? (from talking with a kinesiology professor)

- How do we learn the different "languages" that other sciences use? (from walking the halls where foreign languages are taught)

- How do introductory science classes influence what undergraduate students think a given field is about? (from sitting in an introductory astronomy course taught by a colleague)

The power of the questions, coming from common program experiences and discussed within a supportive group, catalyzed many participants to move to action on their newfound awareness. In one such discussion, the question was raised of how to get students actively involved in class by having them ask questions. A graduate student participant reflected on how her expeditionary learning group explicitly brought to light a challenge she experienced with student involvement in the course. She knew she was having a problem in her class getting students to be more interactive, but she was not able to put her finger on the real issue. "I have [felt the tension] in class, but I didn't notice [why] until it was pointed out in a[n] [expeditionary learning] meeting and [ 1 saw then that] it's true." With the help of the group, she was able to translate her challenges in the classroom into a new insight of power dynamics in the classroom. She had explicitly recognized and named the problem in such a way that she felt better suited to address the issue in class. 


\section{Future Program Changes: Modeling Teaching-as-Research}

The teaching-as-research model emphasizes the need for practitioners to close the loop by revising their teaching based on the information gathered in their formative evaluations. We would be remiss if we didn't model it ourselves with what we have learned about the first run of expeditionary learning. Based on written feedback at the end of the semester, our interviews, and facilitator observations, we have learned many ways to improve the program in future years. Two primary areas of change will be emphasized: more time for discussion and more formalized and defined expeditions.

Discussion time was limited, particularly in one group, because of large group size and scheduling conflicts that dictated a shorter meeting time. The structure for group sharing provided time up-front for each individual to share the story of his or her experience before open discussion allowed all to share, but limited time for deeper discussion as a group. There was scarcely enough time to share the basics of each person's expedition before it was time to think about the next expedition. Experience with other similar programs has shown it is not practical to extend meetings beyond one and one-half hours. Instead of lengthening the meetings, we will keep groups smaller in the next iteration (maximum of seven people), and evaluate the timing of storytelling and discussion.

The amount of guidance the facilitators provided the participants intentionally decreased over the course of the semester. We moved from very well-defined expeditions (e.g., visit a library or a museum), to very open-ended assignments (e.g., develop a question of interest about undergraduate learning and go on an expedition to learn more about it). The purpose of this progression was to gradually build group ownership of the program so it was self-directed rather than expert-driven. The feedback we received in both the end-of-semester evaluations and the interviews overwhelmingly indicated that participants wanted more direction and concrete guidance throughout the semester's expeditions. Several reasons participants gave for wanting more direction were ease of participation, an increased chance for "points of intersection" between participants' similar expeditions to facilitate discussions, and the lack of knowledge about what possibilities existed on campus that answered the questions they had developed for themselves. 


\section{Conclusions: Low Risk, Low Resource Needs, but Potential for High Impact}

We found the time commitment for facilitators and participants seemed reasonable for those who are truly committed to the teaching mission of their work. The number of people to staff the program and the level of experience for facilitators are minimal compared to many other programs that require either more facilitators or a much higher level of experience and expertise in content knowledge. Because the program builds on existing campus resources, expeditionary learning has no financial cost other than a facilitator's time (roughly two to three hours per week). It is already apparent that a few participants are interested in volunteering their time to facilitate future groups as the program grows. Because of the low resource needs and time commitment, the risk to adopt the program on a trial basis is minimal for both the institution and the individuals who participate.

We do not yet know about the lasting impact of this program on participants. However, it seems that certainly some participants were strongly affected by the insights they gained through their participation. As part of our ongoing learning community development of the broader Delta Program in Research, Teaching, and Learning, we are connecting expeditionary learning to other opportunities to support participants who have acted on their insights, such as Greg, the faculty participant in the chapter's opening story. One of the biggest impacts of the expeditionary learning program may be the future connections that isolated teachers make with each other as they come together to form a diverse community of learners directed toward education reform in science, engineering, and mathematics disciplines.

\section{Future Work and New Questions}

A crucial component of teaching-as-research and ongoing program evaluation is developing new questions for continued inquiry and methods to learn more. Among many other very specific logistical issues we will continue to track, some larger-scale questions we will explore next year include:

- What is the effect of the size of the group on the participants' experience?

- What is the effect of different mixes of participants in the groups (i.e., numbers of faculty, postdoctoral fellows, instructional staff, and graduate students)? 
- How is the expeditionary learning experience different for those with teaching experience and those without?

- How is the expeditionary learning experience different for those who are concurrently teaching and participating in the program and those who are not currently teaching?

- How much should the program be participant-driven and how much should be facilitator-driven?

- How can we sustain the program over time (recruitment of participants and facilitators)? How can we help participants sustain the changes they make to their own practice, and to the changes they initiate in their home departments?

These questions will help to guide our ongoing inquiry into the logistics, theory, and implementation of the program. They can guide us on our ongoing expedition and to model for others the process of remaining open to the surprises of this endeavor. A postdoctoral fellow participant commented on the surprises of the program and summed up many of the programmatic themes when she responded to the question "What would you tell someone else about your experience with this program?"

- "It is surprising because you wouldn't necessarily know what you would gain, but you would gain different perspectives that you could apply to your career. [It could help you] if you were interested in teaching, or different ways to look at your research, even different ways to look at yourself. Everyone in the biological sciences goes to lab, does experiments, and does lots of wet bench work. [But] there's a lot of other people on this campus who have a completely different day. [Expeditionary learningl is like a little community of people who are trying to come up with more effective and maybe different, or maybe the same, but effective ways of being teachers and learning about the U[niversity]. If [someone is] interested in teaching, they would gain because of the additional perspectives, but even if they weren't, I think it would be fun."

We close this chapter with a quote from Rachel Naomi Remen, a noted physician who has worked extensively with medical students and practicing physicians to develop comfort with the unexplainable mysteries and surprises of life. She said, "How many people can say 'I don't know' with a sense of adventure rather than a sense of inadequacy?" (Personal communication, September 24, 2003). It is common for self-reflective teachers to have strong feelings of inadequacy without a forum to say safely "I don't 
know." Expeditionary learning exists for many reasons, not least of which is to encourage, support, and nurture teachers in their journey into the mysteries and surprises of inquiring about learning and teaching.

\section{Note}

This material is based upon work supported by the National Science Foundation under Grant No. 0227592.

\section{References}

Allen, C. (1999). Wiser women: Fostering undergraduate success in science and engineering with a residential academic program. Journal of Women and Minorities in Science and Engineering, 5(3), 265-277.

Altschuler, G. C., \& Kramnick, I. (1999, November 5). A better idea has replaced 'in loco parentis'. Chronicle of Higher Education, p. B8.

Apple, M. (1996). Power, meaning, and identity: Critical sociology of education in the United States. British Journal of Sociology of Education, 17(2), 125-144.

Barley, S. R. (1990). Images of imaging: Notes on doing longitudinal fieldwork. Organization Science, 1(3), 220-247.

Boyer, E. L. (1990). Scholarship reconsidered: Priorities of the professoriate. Princeton, NJ: Carnegie Foundation for the Advancement of Teaching.

Brower, A. M., \& Dettinger, K. M. (1998, November/December). What is a learning community? Toward a comprehensive model. About Campus, 15-21.

Brower, A. M., \& Laines, M. J. (1997). What works and how we found out: An assessment of the Bradley Learning Community. Talking Stick, 14(7), 17-19.

Cousins, E. (1998). Reflections on design principles. Dubuque, IA: Kendall/Hunt.

Cousins, E. (Ed.). (2000). Roots: From outward bound to expeditionary learning. Dubuque, IA: Kendall/Hunt.

Cunningham, P. M. (2000). A sociology of adult education. In A. L. Wilson \& E. R. Hayes (Eds.), Handbook of adult and continuing education (pp. 573-591). San Francisco, CA: Jossey-Bass.

Durand, B. (2004, April 11). Diversity plans are in effect. Wisconsin State Journal, p. B1.

Glesne, C., \& Peshkin, A. (1992). Becoming qualitative researchers: An introduction. New York, NY: Longman. 
Henry, J. (1989). Meaning and practice in experiential learning. In S. W. Weil \& I. McGill (Eds.), Making sense of experiential learning: Diversity in theory and practice (pp. 29-33). Buckingham, England: Society for Research into Higher Education and Open University Press.

Koehler, T., \& Miranda, C. (2004, April 11). Are today's UW-Madison graduates cultural klutzes? Wisconsin State Journal, p. B1.

Kolb, D. A. (1984). Experiential learning: Experience as the source of learning and development. Englewood Cliffs, NJ: Prentice Hall.

Mattmiller, B. (1996). A new notion of home. On Wisconsin, 20-39.

Meikeljohn, A. (1928). The experimental college. Madison, WI: University of Wisconsin Press.

Robson, C. (2002). Real world research: A resource for social scientists and practitioner-researchers (2nd ed.). Oxford, England: Blackwell.

Running Wolf, P., \& Rickard, J. A. (2003). Talking circles: A Native American approach to experiential learning. Journal of Multicultural Counseling and Development, 31, 39-43.

Salvendy, G. (Ed.). (1997). Handbook of human factors and ergonomics. New York, NY: John Wiley \& Sons.

Wilson, A. L., \& Hayes, E. R. (2000). On thought and action in adult and continuing education. In A. L. Wilson \& E. R. Hayes (Eds.), Handbook of adult and continuing education (pp. 15-32). San Francisco, CA: Jossey-Bass. 


\section{Appendix 18.1}

\section{Expeditionary Learning Fall 2003 Semester Schedule}

\begin{tabular}{|c|c|c|}
\hline Week of & Preparation Outside of Meeting & Activity During Meeling \\
\hline Sept. 22 & None & $\begin{array}{l}\text { Small group mecting: introductions, } \\
\text { program overview, community agree- } \\
\text { ments, distribute introductory reading }\end{array}$ \\
\hline Sept. 29 & $\begin{array}{l}\text { Read article "Through the Lens of } \\
\text { Learning: How Experiencing } \\
\text { Learning Challenges and Changes } \\
\text { Assumptions About Teaching" } \\
\text { (Brookfield, 1996) } \\
\text { Roundtable dinner on Wednesday, } \\
\text { October 1st, 6:00-7:15 at University } \\
\text { Club }\end{array}$ & $\begin{array}{l}\text { Small group meeting: questions, } \\
\text { discussion of reading, introduction to } \\
\text { expeditions }\end{array}$ \\
\hline Oct. 6 & Go on expedition l & no small group meeting \\
\hline Oct. 13 & $\begin{array}{l}\text { Jot down reflections from your } \\
\text { expedition and roundtable dinner }\end{array}$ & $\begin{array}{l}\text { Small group mecting: discuss expedition } 1 \\
\text { Choose expedition } 2\end{array}$ \\
\hline Oct. 20 & Go on expedition 2 & no small group meeting \\
\hline Oct. 27 & $\begin{array}{l}\text { Jot down reflections from your } \\
\text { expedition }\end{array}$ & $\begin{array}{l}\text { Small group meeting: discuss expedition } 2 \\
\text { Distribute reading for next week's dis- } \\
\text { cussion. (Topic TBA depending on } \\
\text { where group is headed) }\end{array}$ \\
\hline Nov. 3 & Read article given out last week & $\begin{array}{l}\text { Small group mecting: discuss reading } \\
\text { Choose expedition } 3\end{array}$ \\
\hline Nov. 10 & Goon expedition 3 & no small group meeting \\
\hline Nov. 17 & $\begin{array}{l}\text { Jot down reflections from your } \\
\text { expedition }\end{array}$ & $\begin{array}{l}\text { Small group meeting: discuss expedition } 3 \\
\text { Choose expedition } 4\end{array}$ \\
\hline $\begin{array}{l}\text { Nov. } 24 \\
\text { Thanksgiving }\end{array}$ & Go on expedition 4 & no small group meeting \\
\hline Dec. 1 & $\begin{array}{l}\text { Jot down reflections from your } \\
\text { expedition } \\
\text { Roundtable dinner on Wednesday, } \\
\text { December 3rd, 6:00-7:15 at } \\
\text { University Club }\end{array}$ & Small group meeting: discuss expedition 4 \\
\hline Dec. 8 & Jot down final program reflections & $\begin{array}{l}\text { Small group meeting: wrap up discussion, } \\
\text { what's next? Plans for next semester? }\end{array}$ \\
\hline
\end{tabular}

